\title{
Wave -Current Interaction Effects on Tidal Stream Turbine Performance and Loading Characteristics
}

\author{
S C Tatum, C H Frost, M Allmark, D M O’Doherty, A Mason-Jones P W Prickett, \\ R I Grosvenor, C B Byrne, T O’Doherty*
}

School of Engineering, Cardiff University, Queen's Buildings, The Parade, Cardiff CF24 3AA

Tel: 02920875366

tatumsc@cardiff.ac.uk, frostc1@cardiff.ac.uk, odohertydm@cardiff.ac.uk, mason-jonesa@cardiff.ac.uk,prickett@cardiff.ac.uk,grosvenor@cardiff.ac.uk,byrne@cardiff.ac.uk, odoherty@cardiff.ac.uk*

Number of words $-7066 \quad$ Number of figures $-13 \quad$ Number of tables - 0

\begin{abstract}
The transient interaction between tidal currents and the rotation of a horizontal axis turbine rotor have the potential to induce high asymmetric loadings, which are subsequently transmitted to the drive shaft and potentially high speed drive train components. To mitigate the potential for early component failure, analysis of asymmetric loading on marine turbines is therefore fundamental to the design process. To investigate these loads a turbine mounted on a circular stanchion has been used to highlight the effects of introducing more realistic boundary conditions, over a rotational cycle of the turbine. The consequences on the turbine's performance characteristics and crucial structural loading are shown. Depending on their wavelength, waves can also have a significant effect on the overall design decisions and placement of devices. Thrust loading and bending moments applied to the drive shaft can be of the order of hundreds of $\mathrm{kN}$ and $\mathrm{kNm}$ respectively. This leads to the need to not only size the drive shaft and bearings to account for axisymmetric loading or thrust, but to also consider large asymmetric loads.
\end{abstract}

Knowledge of the flow regime can allow designers to evaluate material selection for components (i.e. for blades, etc.) and incorporate some deformation capability of the turbine blades to increase the power output and potentially alleviate some of the stress distribution through key structural points, i.e. drive shaft, bearing connectors, etc. The resulting data can then be used to estimate component life via fatigue prediction.

This paper includes a multi-physics approach to modelling tidal energy devices and the potential for modelling to inform device condition monitoring

Keywords: Tidal turbines, Computational modelling, Fluid structural Interaction.

\section{Nomenclature}

Cp power coefficient (-)

Ct thrust coefficient (-)

$\mathrm{L} \quad$ wavelength $(\mathrm{m})$

$k \quad$ wavenumber $\left(\mathrm{m}^{-1}\right)$

d water depth $(m)$ 


$\begin{array}{ll}\lambda & \text { tip speed ratio }(-) \\ \omega & \text { angular velocity of wave }\left(\mathrm{rad} \mathrm{s}^{-1}\right) \\ \mathrm{g} & \text { gravity }\left(\mathrm{m} \mathrm{s}^{-2}\right) \\ \mathrm{T} & \text { wave period }(\mathrm{s}) \\ \mathrm{h} & \text { wave height }(\mathrm{m})\end{array}$

\section{Introduction}

The EU has targeted renewable energy to provide $20 \%$ of the total energy mix by 2020 [1] in comparison the UK target is $15 \%$ of the UK energy demands from renewable sources by 2020 [2]. In order to meet and sustain the targets set by 2020 and beyond, the UK and EU at large must continue to address the imbalance in the renewable energy mix. The potential for sustainable production through wave and tidal energy conversion has resulted in large investment from industry and governments. A practical and economical resource of tidal current and wave energy resource of 70 $\mathrm{TWh} / \mathrm{yr}$ around the UK shores has been identified, which would contribute to $20 \%$ of UK's total industrial, commerce and domestic electricity demands [3].

The long term predictability of tides is the main advantage of tidal power over other renewable energy sources since it allows any phase change in power productions between wind and or other tidal stream and wave sites to be balanced. The two leading techniques in energy conversion for tidal range power generation are impoundment schemes such as a barrage or tidal lagoon and Tidal Stream Turbines (TSTs). The impoundment schemes offer large scale solutions, as documented in the La Rance Tidal Power Plant run by EDF Energy which produces 0.54 TWh/year [4], whilst TSTs offer bespoke solutions to fit the local environment and since they are submerged, they are less intrusive than impoundment schemes and minimise the impact on the marine and costal environment.

The introduction of TSTs into the UK energy mix can only be a positive step since the UK has some of the strongest currents in the world, with a number of areas identified as viable sites for installing tidal energy devices [3]. Ideal conditions for tidal stream turbines are; a free stream velocity of $2-3 \mathrm{~m} / \mathrm{s}$ and a depth of $20-30 \mathrm{~m}$, at least for early stage implementation with deeper water designs (> $40 \mathrm{~m}$ ) introduced as the industry matures. Current developments include the DeltaStream device which is being installed in the Ramsey Sound, Pembrokeshire [5], and the array, of SeaGen S turbines, in the Skerries site off Anglesey [6]. The success of these initiatives is dependent on a thorough understanding of the hydrodynamic forces applied to the TST, its scale, blade design and experiential knowledge acquired from environmental monitoring, which for example has led to actively pitch controlling the blades to limit the maximum rotational speed of the rotors to $14 \mathrm{rpm}$ [7]. The hydrodynamic forces cause considerable loading on the blades, resulting in blade deformation. The magnitude of the deformation will be dependent on the design of the blades, their internal structure and materials used. However, the combined loading on the blades and nose cone of the rotor is transmitted to the drive shaft, and knowledge of these resultant transient forces is essential for developers to optimise the success of their design. 
The simplest scenario for determining the hydrodynamic forces is to consider the effects of a uniform tidal current. However, in reality, the current is typified by a high shear in the velocity profile through the water column, turbulence and surface waves and these all need to be considered in determining the loads on a TST. Work on the effects of highly shearing profiles and levels of turbulence have been considered by Mason-Jones et al, 2008 [8] and Morris, 2014 [9]. Wave effects are likely to be critical as they are known to penetrate the water column to a depth of approximately $50 \%$ of their wavelength [10]. This can be further complicated by the fact that the direction of the wave does not necessarily align itself to the direction of the current as shown by Lewis et al, 2014 [11].

Myers and Bahaj [12] provided a clear indication, shown in Figure 1, of the primary flow characteristics of the tidal current. The scale of the variations in the bathymetry has a significant effect of the shape of the flow profile through the water column. The greater the drag effects, the potentially greater the velocity shear. Sea surface gravity waves result in an oscillatory motion under the water surface. If particles are considered to be suspended through the water column, they would move in an elliptical fashion with the magnitude of the oscillations diminishing with distance from the water surface, with motion ceasing at a depth of approximately half the wavelength of the wave .

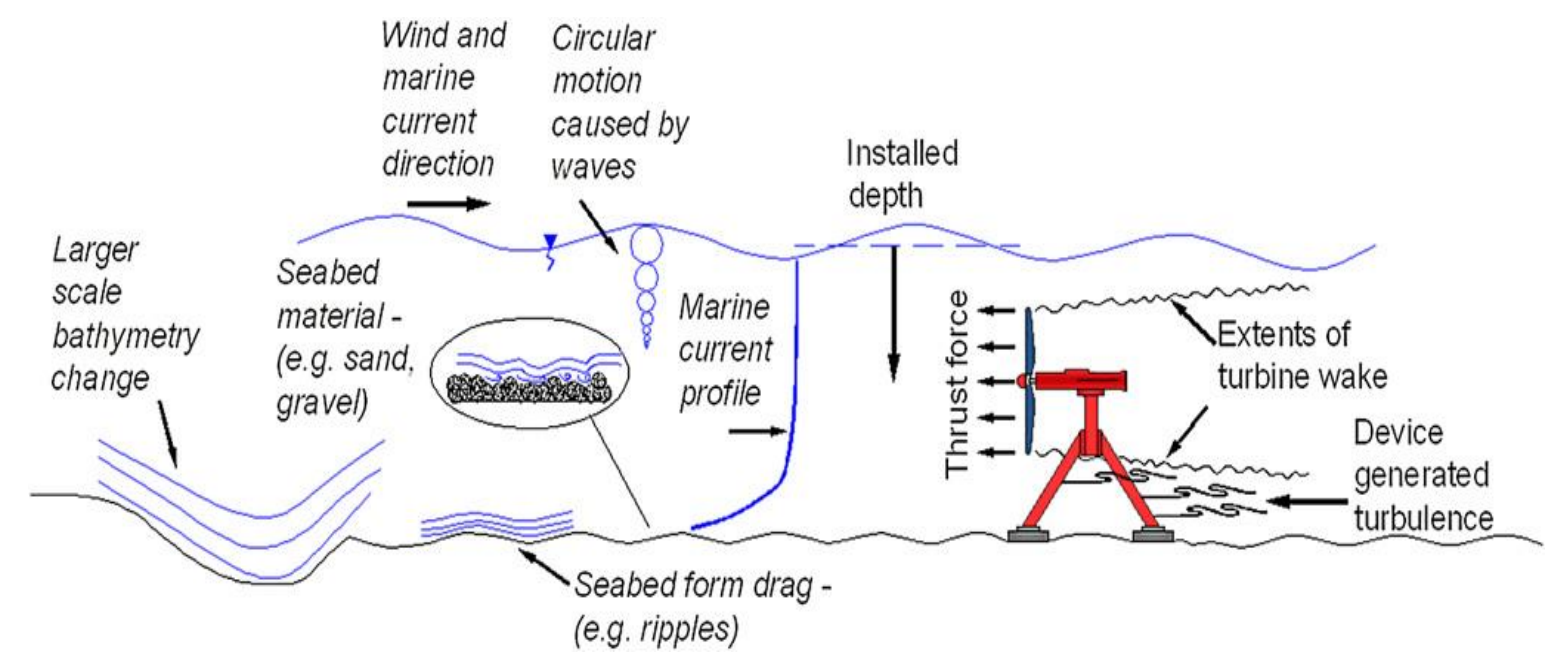

Figure 1 Variables affecting the flow field around tidal turbines [12].

The aim of this work was therefore to investigate, by the means of numerical modelling, the effects of surface waves on the performance characteristics of a tidal turbine. The approach taken started with steady state uncoupled CFD modelling of the turbine through a range of tip speed ratios $(\lambda)$ for constant current flow (the uncoupled CFD model), followed by a fully coupled 2-way transient FSI model at peak power for the same current flow (the FSI model). Finally a transient uncoupled CFD model was modelled at peak power for the same current flow, with waves in the same direction as the current (the VOF model). In all cases, the study focussed on the cyclic blade loading from axial thrust loads. 


\section{$2 \quad$ Fluid structural interaction modelling (FSI)}

Previous FSI studies of marine turbines include a loosely coupled approach, via a surface panel code to link the CFD to the FEA [13]. This work gives a valid insight to the effects of FSI and its consequences on cavitation, power attenuation and stresses on the structure. While it is stated by Nicholls-Lee et al, 2011 [13] that the panel method performs well for undeviating flows, it becomes necessary to include intricacy in the hydrodynamic flow field, such as the RANS, DES and LES solvers to accurately capture the hydrodynamics. Moreover, with knowledge of the hydrodynamics under extreme conditions it becomes necessary to consider the strong coupling effects between the fluid and the structure. These issues were addressed using a fully coupled 2-way FSI model using a symmetry boundary and single blade by Park et al, 2013 [14]. From the results it was suggested that although the deflection of the blade was relatively small in their study, it was still necessary to consider blade deformation due to a $1.7 \%$ drop in maximum power extraction. Morris, 2014 [9] established the performance characteristics of a tidal stream while allowing for blade deformation a series of quasi-static coupled 2-way FSI models constructed with a homogenous blade material, each subjected to a uniform flow inlet boundary condition. The kinetic energy extraction and its sensitivity to structural stiffness attenuation were investigated by incrementally reducing the materials Young's modulus and noting its effect on the rotor's performance.

\subsection{Geometry specifications}

The $10 \mathrm{~m}$ diameter, 3 bladed steel TST discussed in this paper, utilised a Wortmann FX 63-137 profile, with a $33^{\circ}$ twist from the blade root to tip. The blade pitch angle was set to the optimum of $6^{\circ}$. The turbine support structure used was of a simple cylindrical design, based on the work of MasonJones et al, 2012 [15] and consisted of a $2.4 \mathrm{~m}$ diameter stanchion as shown in Figure 2. Based on the work of Frost et al, 2014 [16], the turbine rotor was positioned with a clearance of $\sim 2 \mathrm{~m}$ from the stanchion and was orientated to be aligned to the tidal flow.
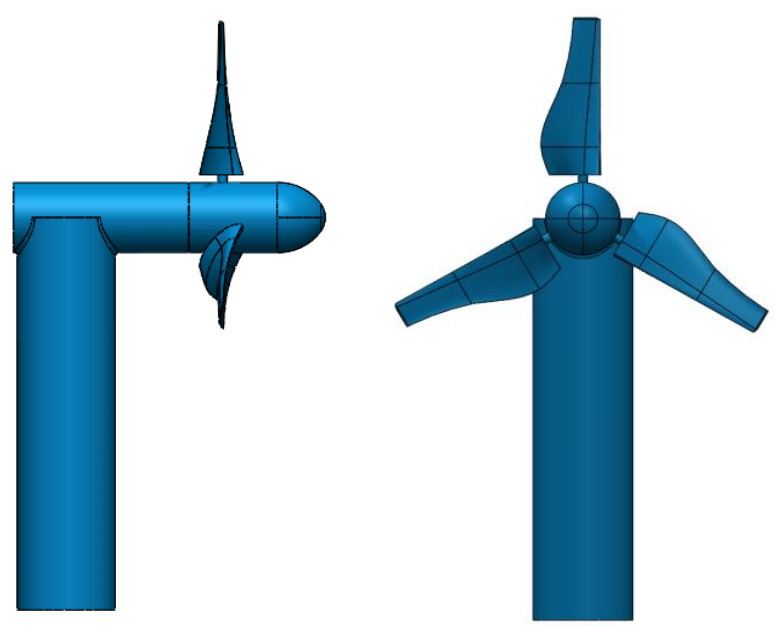

Figure 2. Side and front view of turbine-stanchion arrangement for all the models. 


\subsection{The uncoupled CFD model}

The uncoupled CFD model consisted of a rectangular domain, $350 \mathrm{~m}$ long x $50 \mathrm{~m}$ wide $\times 35 \mathrm{~m}$ deep. The turbine was located $100 \mathrm{~m}$ downstream from the inlet boundary such that its rotational axis was set at $25 \mathrm{~m}$ below the water surface. An axially aligned cylindrical domain was subtracted from the rectangular domain to form a rotational interface domain with a non-conformal interface between the sea and turbine volumes to model the rotation of the turbine. The blade surface interfaces were modelled using tetrahedral elements with face sizing of $0.01 \mathrm{~m}$ for the top third and $0.02 \mathrm{~m}$ for the bottom two thirds, leading to the root. The rotational interface domain was set with an internal body size of $0.2 \mathrm{~m}$ the same value was applied to the external faces of it. In total the water domain had 3.5 million elements with 2 million concentrated about the rotational interface and turbine surfaces. The uncoupled CFD models have been previously validated using a recirculating water flume and an uncoupled CFD model $[16,17]$.

Inlet boundary conditions were defined as a simple uniform flow of $3.086 \mathrm{~m} / \mathrm{s}$ (6 knots). The outlet was a pressure outlet, set to atmospheric pressure or $0 \mathrm{~Pa}$. All walls of the domain were set to free slip, apart from the seabed which was set to a 'no slip' wall boundary.

For this and subsequent CFD models, the Reynolds Averaged Navier-Stokes equations were applied to relate the Reynolds Stresses to the mean velocity gradients. To close the equations the Shear Stress Transport (SST) was used as the viscous model. Previous work has used the Reynolds Stress Model as the viscous model; however the SST was used due to the increased model complexity and computational expense of FSI and free surface modelling. The SST model was also found to have a turbulence dissipation rate more suited to this work and had the added benefit of being computationally less expensive [9].

\subsection{The FSI model}

The FSI model utilised the same domain definition as the uncoupled CFD model for the CFD analysis whilst the mesh for the FEA analysis had the same face sizing on the blade surface interfaces and hub interface as the CFD model in order to limit mesh mapping errors for the transfer of data. The face and body cells of the rotating domain in which the turbine was located were sized at $0.2 \mathrm{~m}$, and the support structure cells were $0.1 \mathrm{~m}$ on the faces and $0.05 \mathrm{~m}$ along the edge. The body of the sea domain was meshed with a coarse element size of $10 \mathrm{~m}$. Hence the final mesh yielded $\sim 1.2$ million cells in the sea domain and $\sim 2.4$ million cells in the turbine domain. The interface boundaries for the data transfer were set to receive the total mesh displacement from the FEA model and send the total force back from the CFD model.

The setup of the boundary conditions for both the FEA and CFD was done sequentially beginning with the FEA model which was set to match the requirements of the CFD model. That is, a rotational velocity of $2.25 \mathrm{rad} / \mathrm{s}(\lambda=3.64)$, which is the angular velocity at which peak power is extracted for this turbine configuration. (To ensure that the blade tip deflection occurred gradually, allowing the mesh to 'adjust' to the new geometry, the angular velocity was ramped up to the required value). The fluid 
structural interfaces were then specified, with each blade separated into two faces, front and back. The labelling of these faces is significant as they are required to set the data transfer from the CFD to the FEA and vice-versa. The foot of the stanchion was fixed to the floor, using a fixed support. It was assumed for this case that there is no movement of the foundation and the entire bottom face of the stanchion would remain in contact with the seabed. Although not discussed in this paper, it is worth noting that the FEA model also had a number of outputs including the total deformation, equivalent stress (Von-Mises), equivalent elastic strain, fatigue life and biaxiality, etc. to provide the hydrodynamic effects on the structure.

Once both the CFD and FEA models were setup they were linked/coupled, thus enabling data transfer between the two models. Coupling was set to suit the CFD model with appropriate time steps for the total time equivalent to approximately 6 full turbine rotations. The 6 rotations of the turbine were required to ensure the transient models had 'settled'..

\subsection{The VOF model}

The VOF model was based on the same definition as the uncoupled CFD model for the water domain, but an additional air domain $350 \mathrm{~m}$ long $\times 50 \mathrm{~m}$ wide $\times 15 \mathrm{~m}$ deep was added on top of the water domain to allow for a Volume of Fluid (VOF) based analysis. The body of the sea domain was again meshed with a coarse element size of $10 \mathrm{~m}$. An additional, more refined inflation, region was added at the location of the free surface and through a thickness of $8 \mathrm{~m}$ to account for the $6 \mathrm{~m}$ height of the wave. The turbine was again meshed with a much finer face element size of $0.01 \mathrm{~m}$ at the tip, increasing to $0.02 \mathrm{~m}$ at the root and hub. The face and body cells of the rotating domain in which the turbine was located were also sized at $0.2 \mathrm{~m}$, with the support structure cells of $0.1 \mathrm{~m}$ on the faces and $0.05 \mathrm{~m}$ along the edge. As can be seen in Figure 3 an air domain was added above the sea domain with 71,893 cells. An inflation layer was applied to the top surface of the water and the bottom surface of the air domain, extending 40 layers into the mesh to allow a much more densely packed mesh in that region. This yielded a final mesh size of $\sim 3.6$ million cells in the sea and turbine domains, as with the previously described FSI model and a total mesh size of $\sim 3.65$ million cells.
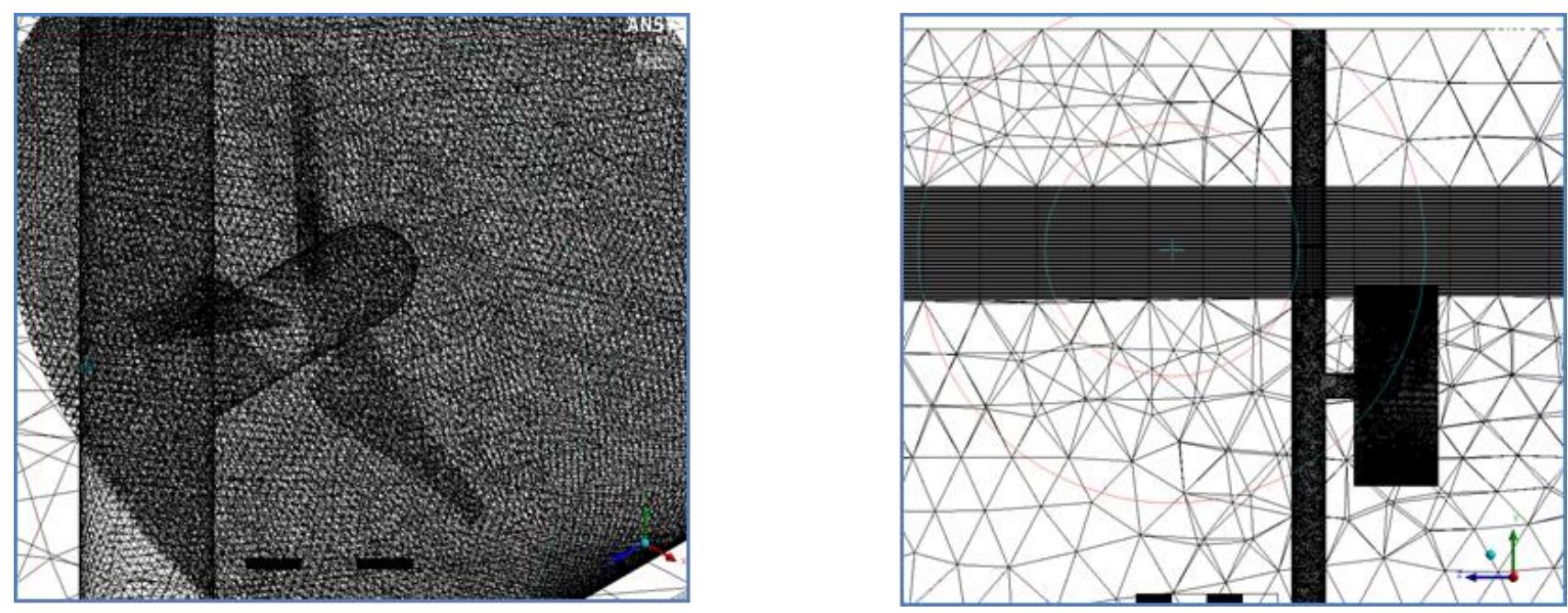

Figure 3. Meshing arrangement for the VOF. 
Sea wave characterisation was carried out with real data, shown in Figure 4, from the British Oceanographic Database [19] in order to determine the parameters for a realistic, but extreme case, sea wave that might be expected to occur. This was carried out by analysing the significant periods and wave heights of various waves measured at multiple locations around the Welsh and West coasts. When analysed by non-dimensionalising the wave height and depth and comparing the results to the graph shown in Figure 5 [20] it was found that the waves fall outside of the linear regime, due to the assumption of linear theory that the amplitude of the wave is very small. $A$ modification of linear Airy theory was applied, to account for the non-linearity of the waves due to their high amplitude of $3 \mathrm{~m}$, known as Wheeler stretching [21]. This modification of Airy theory was found to yield an acceptable approximation to the expected sub surface orbital water motion by stretching the vertical coordinate and applying the kinematics at the mean water height throughout the water column.

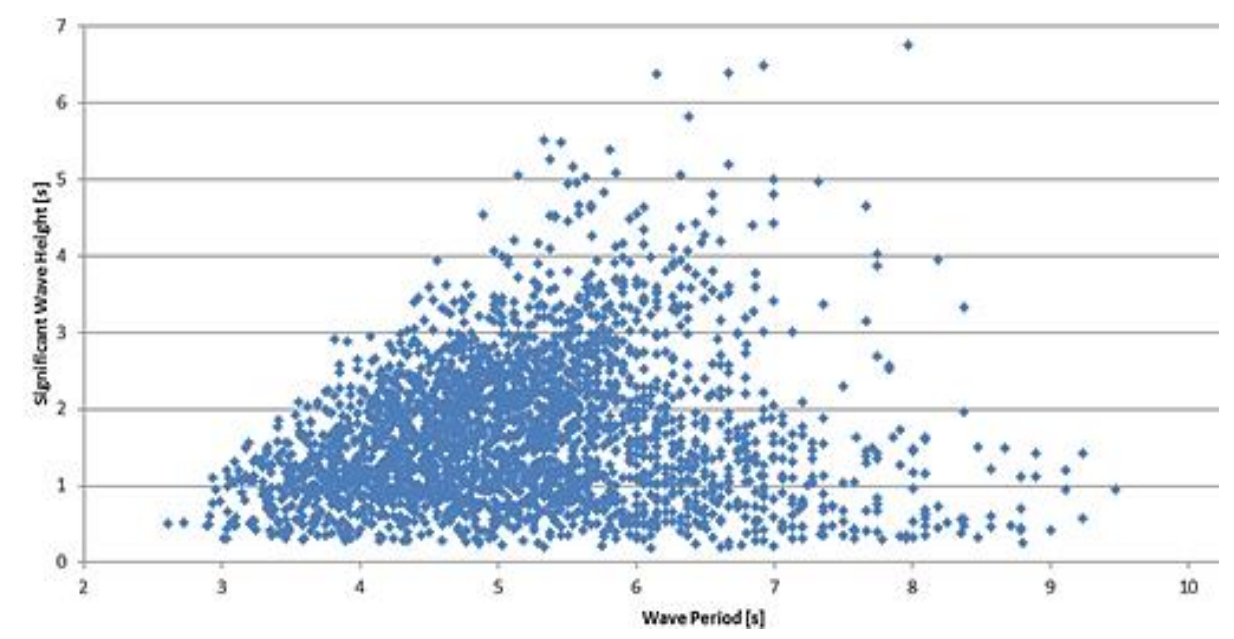

Figure 4. Scatter plot of waves at Gower based on their significant periods and wave heights [19].

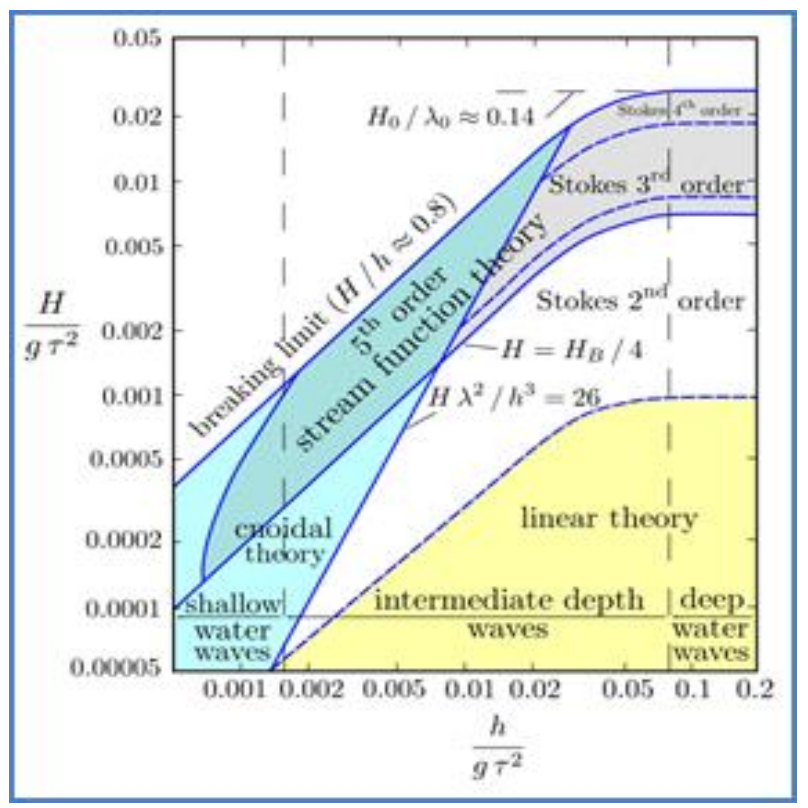

Figure 5. Non dimensionalised water depth and wave height to determine wave regime [20]. 
The boundary conditions defining the height of the free surface as well as inlet conditions were specified. The outlet was set as an opening, as this prevents reflection of the waves disrupting the domain and allows the sub-surface wave motion to move back and forth in an orbital fashion Nondimensionalisation of the wave height and water depth was achieved by dividing by gravitational acceleration and the square of the wave period, which was then compared to the work found in the literature to confirm the non-linear nature of the waves in this study [20, 22, 23].

In order to specify the wave using linear theory, the wave number $\mathrm{k}$ was required. This was calculated from the dispersion relation (equation 1.1), which specifies that a wave of a particular frequency must have a given value of $k$, defining the wavelength (equation 1.2) [23].

$$
\begin{aligned}
& \omega^{2}=g k \tanh (k d) \\
& \mathrm{L}=\frac{2 \pi}{k} \\
& \mathrm{kd} \tanh (\mathrm{kd})=\frac{\omega^{2} d}{g}
\end{aligned}
$$

An inverse tanh function based on a set of data pairs for $(k d)$ and tanh(kd) was then used to determine the wave number from equation 1.3, given that the right hand terms are known or can be calculated [23]. The wave height was selected to be small enough that quasi-linear theory was sufficient to describe it, but large enough that its graphical representation and effects were visibly observable.

The other constraint was that the wavelength needed to be sufficiently large for the effect of the wave to penetrate to the turbine depth. Consequently a wavelength of $30 \mathrm{~m}$ was chosen, giving a wavenumber, $\mathrm{k}=0.209 \mathrm{~m}^{-1}$. Given the depth of water was $35 \mathrm{~m}$, the angular velocity was calculated as $1.43 \mathrm{rad} / \mathrm{s}$, giving a time period of $4.38 \mathrm{~s}$.

The rotational speed of the turbine was once again set to $2.25 \mathrm{rad} / \mathrm{s}$ to allow direct comparison with the uncoupled CFD model. Hence a single turbine revolution takes approximately $2.79 \mathrm{~s}$, thus the the turbine rotates approximately 1.6 times per wave.

\section{RESULTS}

\subsection{Performance curves}

The turbine performance characteristics were determined from the thrust and power curves plotted from the results obtained from the quasi-static model used in the uncoupled CFD analysis. Figure 6 shows the results of both the power and thrust coefficients for the turbine with the simple support structure, which agree with previously published data that used the Reynolds Stress Model as the viscous model, i.e. peak $\mathrm{Cp} \sim 0.41$ at $\lambda=3.64$ and peak $\mathrm{Ct} \sim 0.80[17,18]$.

Comparing the $\mathrm{Cp}$ and $\mathrm{Ct}$ values at peak power, it can be seen that when the CFD analysis is undertaken as part of the FSI model and consequently changed to a transient model, the value of 
both these characteristics increases. The small increase in the power output with the FSI model to $480 \mathrm{~kW}(\mathrm{Cp}=0.43)$ is due to deformed shape of the blades which deflect away from the non-loaded setting [9]. There is no significant change in the thrust with this level of blade deformation. However, as shown by Morris, 2014 [9], an increasing blade deflection results in a reduction in the level of thrust, which again should be expected as the projected area reduces.

Likewise there is a similar increase in the time averaged Ct at peak power for the VOF model, though the time averaged $\mathrm{Cp}$ at peak power has reduced for the VOF model. From Figure 6 it can be seen that the addition of the waves reduces the power to a mean value of approximately $440 \mathrm{~kW}(\mathrm{Cp}=$ $0.38)$, a $4 \%$ reduction.

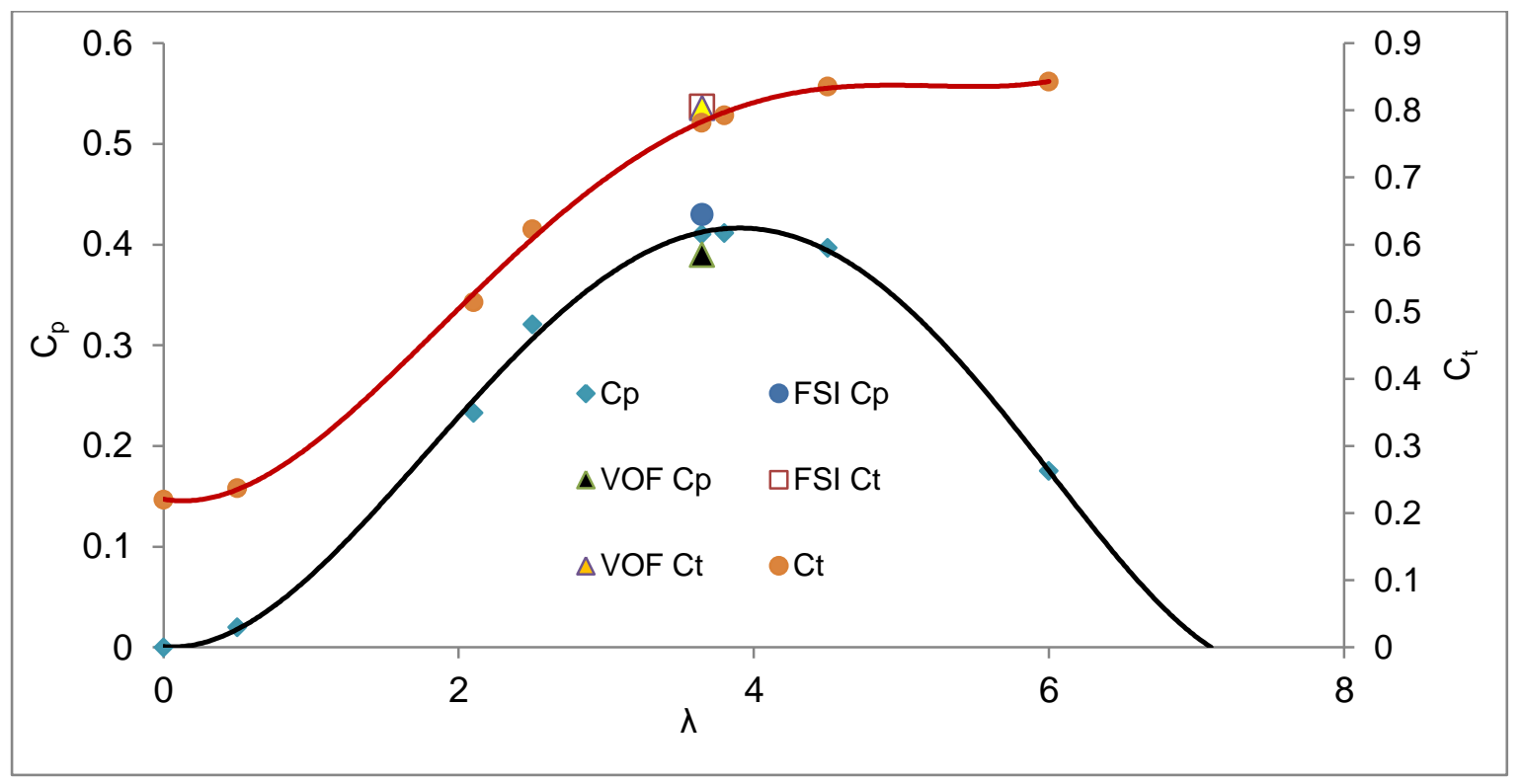

Figure 6. Turbine performance characteristics (uncoupled CFD) with peak power and thrust values for the VOF and FSI models.

\subsection{Thrust}

Figure 7 shows that the transient thrust force for the FSI model is reasonably constant, save for the rotational position when the blade and stanchion have a small level of interaction. The interaction per blade is once every rotation with a frequency of $0.35 \mathrm{~Hz}$. Hence a complete rotation of the three bladed turbine has a frequency of $1.05 \mathrm{~Hz}$. The black line is a dimensionless representation of the wave position at the turbine and the turbine images depict the blade configuration at each given time.

The amplitude of the thrust on an individual blade is approximately $240 \mathrm{kN}$. However the combined thrust which is transferred to the drive shaft is approximately $300 \mathrm{kN}$ (Ct $\sim 0.80$ ), with a $5 \mathrm{kN}$ fluctuation. This thrust and that on the hub will ultimately be transmitted to the structural support. The hub loading is negligible compared to the blade loading.

The addition of a surface wave to the environment (VOF model) can be seen to have a large effect on the thrust loading The net thrust transferred to the drive shaft is virtually the same as that when there is no surface wave present (FSI model) as can be seen in Figure 6. However the simple repetitive fluctuation previously seen has been complicated by the addition of a second periodic event, which 
has a longer time period, is not a multiple of, and out of phase of that of the turbine rotation. The maximum thrust has also increased to $318 \mathrm{kN}(\mathrm{Ct} \sim 0.85)$ with a $48 \mathrm{kN}$ amplitude. However there is an additional long 'enveloping' wavelength that occurs as a result of the wave - turbine rotation combination. The frequency of this wavelength is $0.14 \mathrm{~Hz}$, with an amplitude of $76 \mathrm{kN}$.

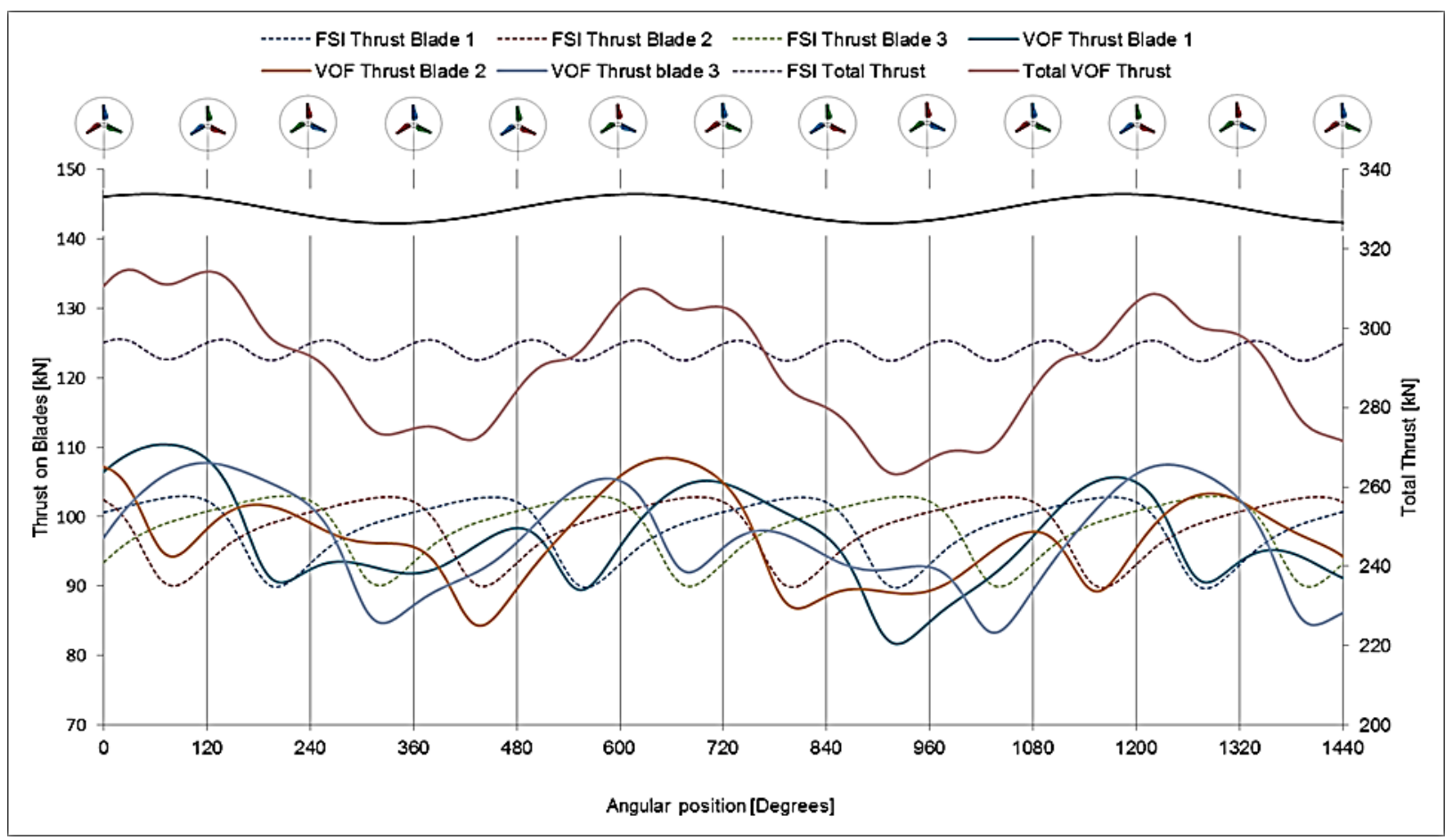

Figure 7. Transient thrust curves for the VOF and FSI models.

The top black line represents the peaks and troughs of the passing wave

\subsection{Power}

The power generated, with no waves present (FSI model), follows a similar trend to that of the thrust data, albeit a very slightly increased average. This is attributed to the small deflection present in the blades which have moved the blade pitch angle to the optimum value [9]. That is to say that there is a regular set of curves from each blade $120 \cong$ out of phase with each other. Hence the power generated by the whole rotor is a clean repetitive power output of approximately $460 \mathrm{~kW}$ (i.e. $\mathrm{Cp} \sim 0.41$ ). The frequency of the oscillation in power (approximately $12 \mathrm{~kW}$ ) matches the rotational frequency of the turbine, i.e. $0.36 \mathrm{~Hz}$. The introduction of waves reduces the power output to $450 \mathrm{~kW}$ (i.e. $\mathrm{Cp} \sim 0.39$ ). The oscillation in the power, $\sim 190 \mathrm{~kW}$, has a frequency of $0.75 \mathrm{~Hz}$. However there is again a longer wavelength apparent which results from the wave-turbine interaction. This influence of the waves on the turbine also means that the peak power output does not always occur at the same rotational position of the blades or with the same magnitude. From Figure 8 it can be seen that the power peaks between one and two full rotation of the turbine for the given environment. This is in contrast to the environment with no waves, where the power peaks 3 times every full rotation of the turbine.

There is a small increase in the power output with the FSI model $(\mathrm{Cp}=0.43$, i.e. $480 \mathrm{~kW})$ which can be seen in Figure 6. This is in agreement with the findings of Morris (2014) [9], for the 3-bladed TST, who showed that the blade deflects away from the non-loaded setting and that there is a very small 
change in the power initially increasing as the blade deforms into an optimal position, after which point there is a drop in power output. There is no real increase in the thrust with this level of blade deformation, which is to be expected. However as shown by Morris [9] as the blades deflect the level of thrust reduces, which again should be expected as the projected area reduces.

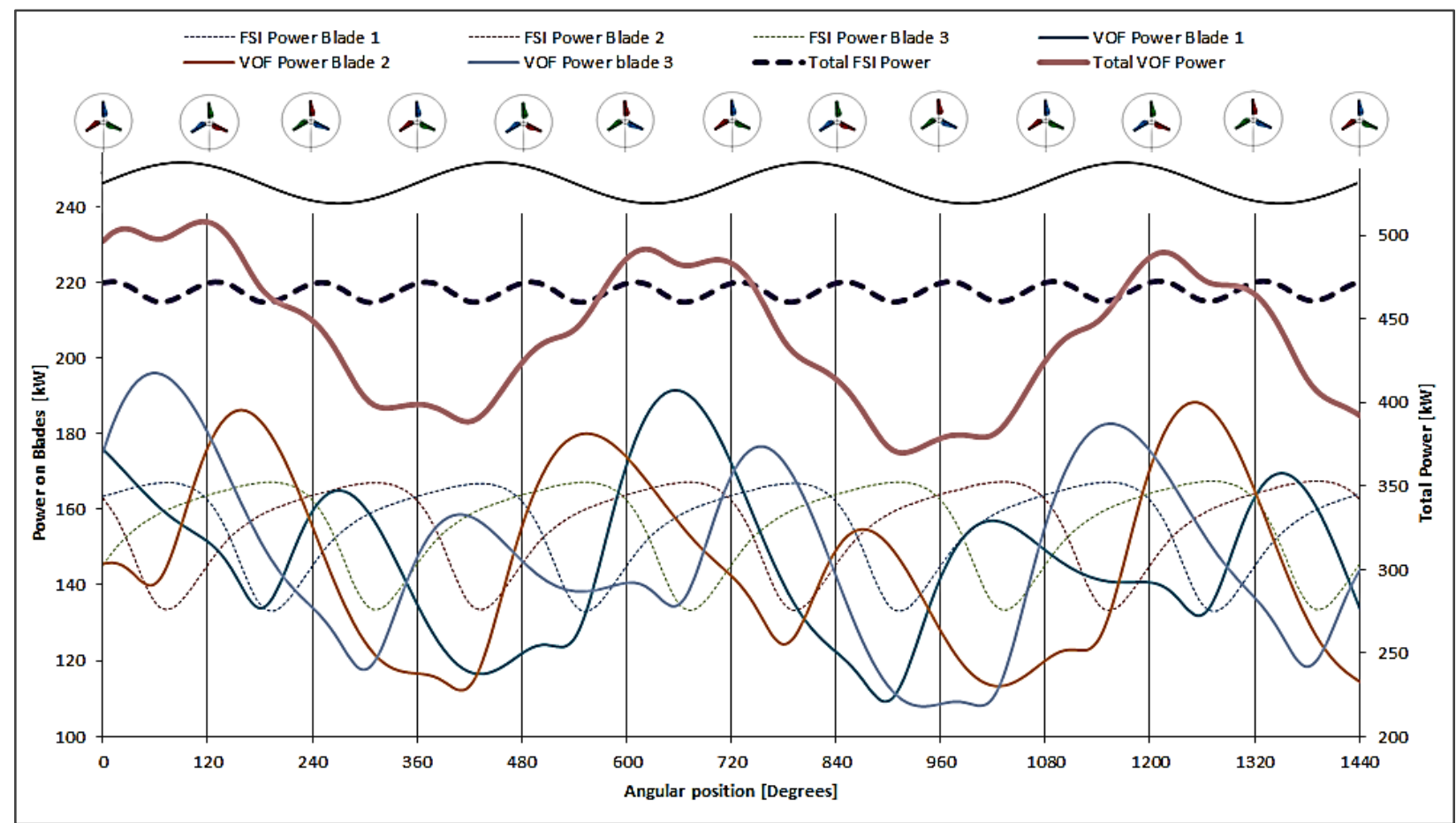

Figure 8. Transient power curves for the VOF and FSI models.

The top black line represents the peaks and troughs of the passing wave.

\subsection{2 way coupled FSI}

Over the complete rotational cycle the blade tips deflection oscillates upto a maximum of approximately $23 \mathrm{~mm}$. Since the velocity is a uniform profile the oscillation is induced by the presence of the stanchion. This is due to the fact that as each blade passes the stanchion its thrust and power is reduced (as represented in Figures 6 and 7) thus causing a variation in blade deflection. This deflection is particularly low due to the material used in the blade model (steel with a Modulus of Elasticity of $200 \mathrm{GN} / \mathrm{m}^{2}$ ). However, the findings are indicative of the loading distribution through the blades and hub.

Given the constantly varying loads that the blades are exposed to due to the wave and stanchion interaction these deflections would also be constantly changing over a rotational cycle. Although the changes in the deflections may be small there is an increased likelihood of fatigue failure and a lower life expectancy of the component parts. This will only be exaggerated by a shearing flow through the water column.

\subsection{Bending moments}

Figure 9 shows the resultant bending moment applied to the turbine drive shaft due to the unequal thrust loading of the tidal flow on the turbine blades. The data shown are from the VOF model and the 
FSI model respectively. The magnitudes of the bending moments are, on average, the same at 26 $\mathrm{kNm}$. However, what is clear from the figure is that the FSI model, which is not influenced by waves, fluctuates between 12 and $36 \mathrm{kNm}$, whereas the introduction of waves (VOF model) increases this fluctuation to between 6 and $45 \mathrm{kNm}$.

The angle of the bending moment is defined as zero when a blade is vertically upwards at top dead centre' and increases in the direction of the turbine's rotation. The range of the direction of the bending moment for the $\mathrm{FSI}$ model is between 5 and $67^{\circ}$, with an average of approximately $37^{\circ}$. Given that the velocity is uniform the variation in angle and the fact that it remains in the upper 'quarter of the rotation' implies that the stanchion has influenced this characteristic. In contrast the introduction of the waves (VOF model) has altered the range of the bending moment direction to

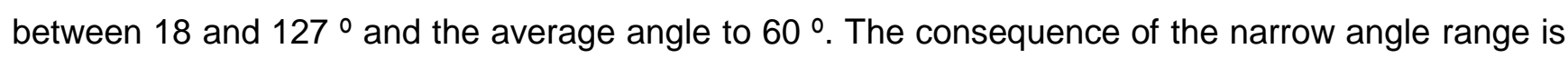
that the bending moment will translate into loading being applied over a small area of the seals and bearings at the rotor end, resulting in uneven wear and possibly reduced life and increased maintenance requirements.

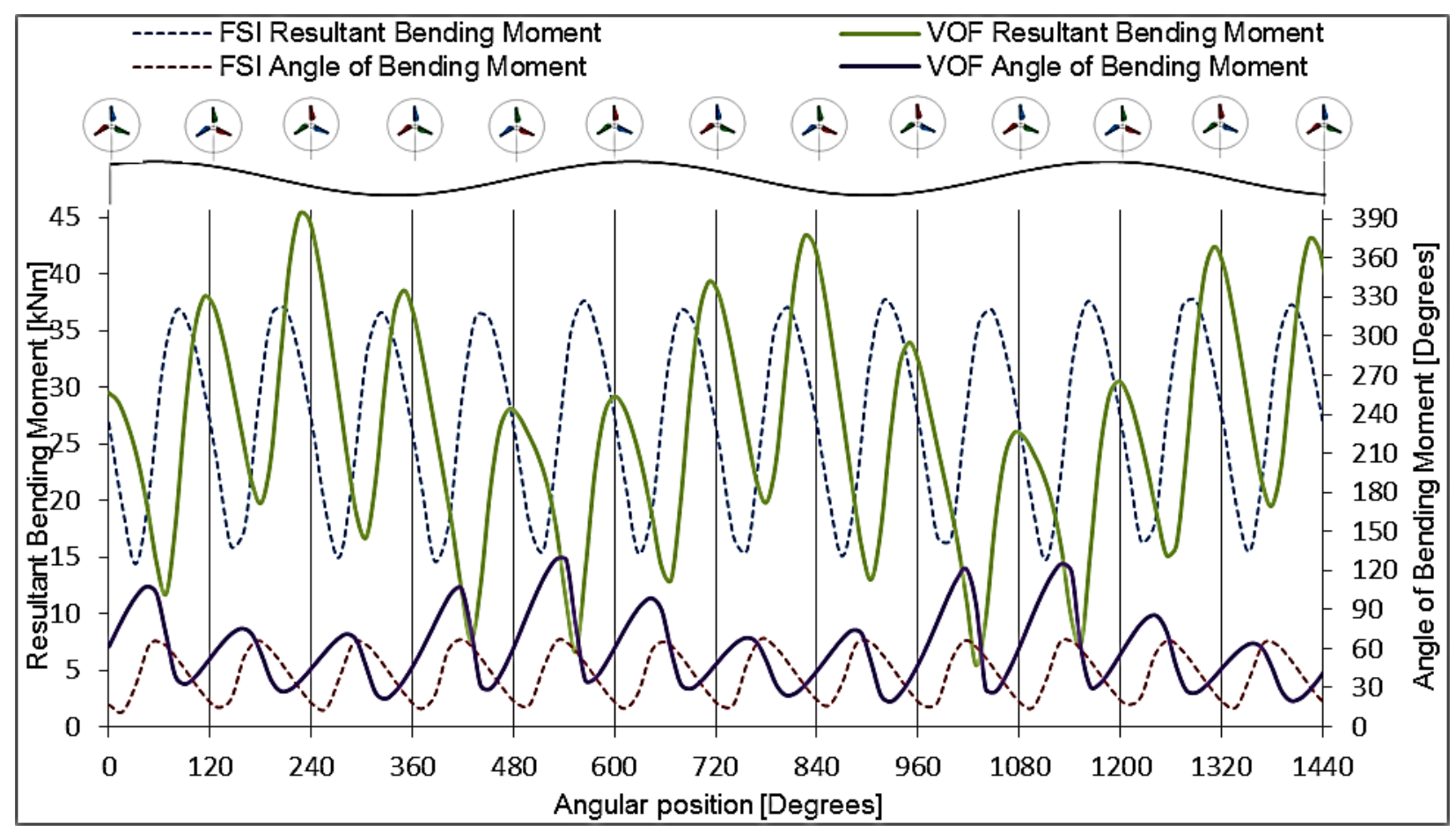

Figure 9. Transient bending moment for the VOF and FSI model.

The top black line represents the peaks and troughs of the passing wave.

\subsection{Life Fatigue}

Given the constantly varying loads that the blades are exposed to due to the wave interaction these deflections would also be constantly changing over a rotational cycle. Even though the changes in the deflections may be small there is an increased likelihood of fatigue failure this will only be exaggerated by a shearing flow through the water column, hence further reducing the life expectancy of component parts. Figure 10 shows an indication of the level of biaxiality or effectively the 
distribution of the stresses through the turbine rotor and nose cone, and therefore highlighting possible failure modes. The red indicates pure tensile stress $(+1)$ and the blue pure compressive stress (-1). As the indicator 'moves' towards the zero there are areas of increasing shear stress.

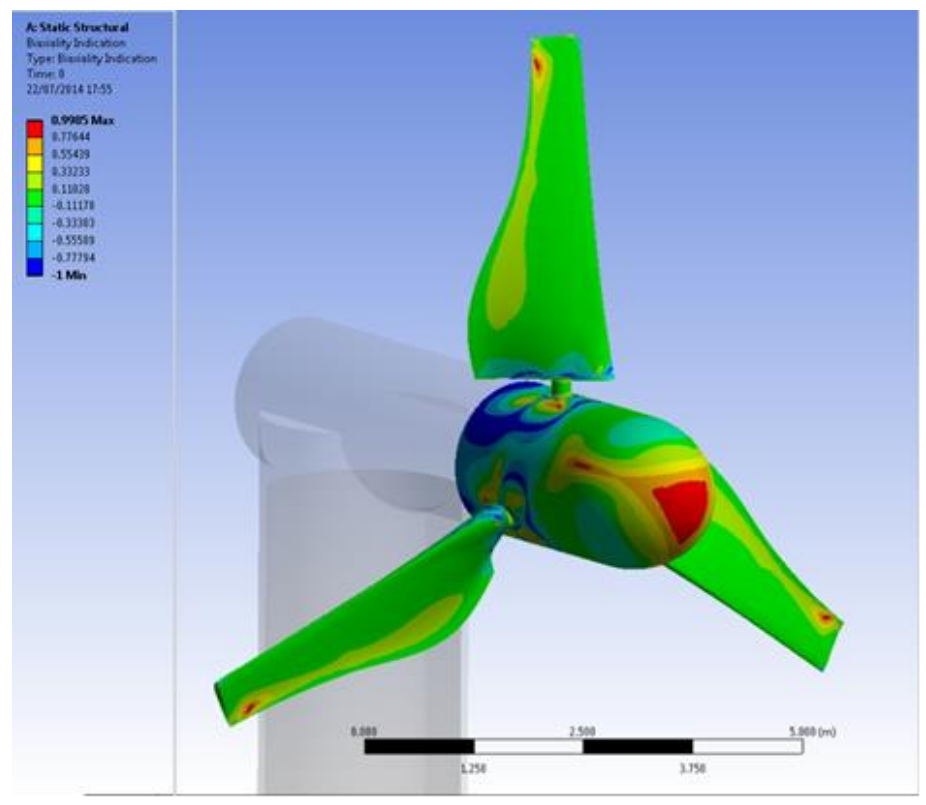

Figure 10. Biaxial Indication.

Figure 11 is a life fatigue prediction derived from the calculated strains in the structure. This is based on a fully reversible event, i.e. one cycle is considered to include flood and ebb tides. Hence if the loading history is considered to be 1.0 then the total cycles is $5.67 \times 10^{4}$ or 77 years. The length of this is not realistic and is purely down to the simplicity of the structural model and hydrodynamics - but does highlight the benefits of a 2 way coupled FSI model.

The life prediction shown in Figure 11 only described the simple conditions which would be experienced by a simple rotation through uniform velocity profile. By adding the loading of even a simple surface wave to the rotating turbine and the loading amplitudes are magnified and the output wave forms of thrust, bending moments and power become complex and will be investigated in future studies. 


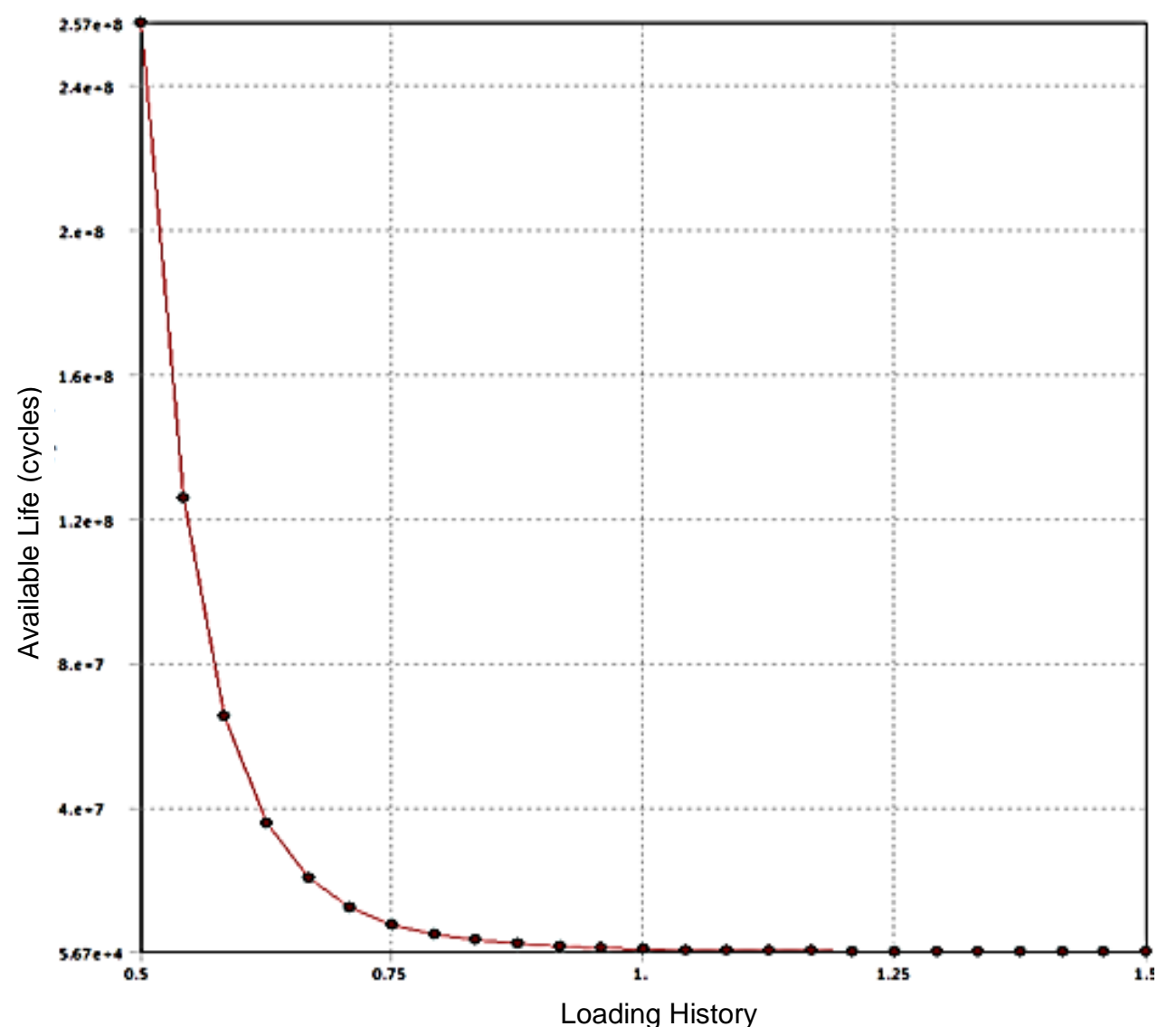

Figure 11. Life prediction curve.

\subsection{Frequency Analysis of Loading Characteristics.}

In order to further investigate the turbine power output and loading characteristics, under the aforementioned model conditions, frequency analysis was undertaken via the Discrete Fourier Transforms (DFT) [24, 25]. The datasets produced from the CFD exercise posed limitations on the underlying frequency resolution achievable via such an analysis. This was due to the length of the data sets which were roughly 11 seconds of converged data. This allowed for a frequency resolution which could not be resolved into the frequency bands of interest - namely, the rotational frequency of the turbine and the frequency of the simulated wave. In order to overcome this limitation the datasets were periodized to 4 times the original datasets. This allowed for a frequency resolution of four times the original resolution thereby resolving the spectrum into the frequency bins required for the analysis.

Figures 12 and 13 show the frequency spectrum of the axial thrust on the turbine rotor for the FSI (steady) and VOF (wave) models, respectively. The blue trace shows the thrust spectrum for a single blade whereas the red trace shows the resultant axial thrust spectrum. In both cases clear peaks are observable at the frequencies of interest, specifically at the rotational frequency of the turbine, 0.358 $\mathrm{Hz}$ (along with second, $0.717 \mathrm{~Hz}$ and third harmonics, $1.075 \mathrm{~Hz}$ ) and in figure 13 the frequency of the wave loading is also observable.

In the case of the FSI model and steady flow conditions it can be seen, as expected, that the observed fundamental frequency is coincidental with rotational velocity of the turbine at $0.358 \mathrm{~Hz}$. In the resultant case the fundamental frequency is at three times the rotational velocity of the turbine, 
$1.075 \mathrm{~Hz}$. This result can be attributed to the shift of the periodic thrust time-series due to the $120^{\circ}$ separation of the blades. This shift in the time series for each blade leads to an associated phase shift in the frequency domain by $\pm 120^{\circ}$ [24]. The phase shift has resulted in deconstruction of the loading contribution from each individual blade at the rotational frequency $(0.358 \mathrm{~Hz})$ and twice the rotational frequency $(0.717 \mathrm{~Hz})$ of the turbine. This deconstruction leads to the low amplitude (approx. $0 \mathrm{kN}$ ) of the turbine rotational velocity and its $2^{\text {nd }}$ harmonic in the resultant loading spectrum. Furthermore the phase shift leads to the construction of the individual blade loading characteristics at three times the rotational frequency of the turbine. Again this leads to the frequency characteristics observed in the resultant loading spectrum - specifically the $5.6 \mathrm{kN}$ amplitude observed at $1.075 \mathrm{~Hz}$.

Figure 13 shows clearly that, in the VOF model data, the wave loading generates the most significant harmonic contribution to the axial thrust loading on the turbine. This is apparent in the first three peaks of the axial thrust load spectrum. The load-frequency characteristics associated with the wave are distributed over three frequency bands. The bands consist of two lower frequency components at $0.089 \mathrm{~Hz}$ and $0.178 \mathrm{~Hz}$ with the third and most significant peak at $0.267 \mathrm{~Hz}$, which is approximately equal to the wave frequency. The thrust loading fluctuations associated with the turbine rotation can also be observed, albeit with less significance in terms of the overall load spectrum. The constructive and destructive interference observed in the FSI model data, due to the associated phase shifting, has been disrupted by the presence of the simulated wave. This resulted in higher load fluctuations at the rotational frequency of the turbine $(0.358 \mathrm{~Hz})$ in the resultant load spectrum. The effect of the wave load has, over the lower frequency ranges, resulted in a more complex spectrum with more disparate loading frequencies. This scenario, in reality, could be far more varied and complex given the wave spectra observed under realistic sea conditions.

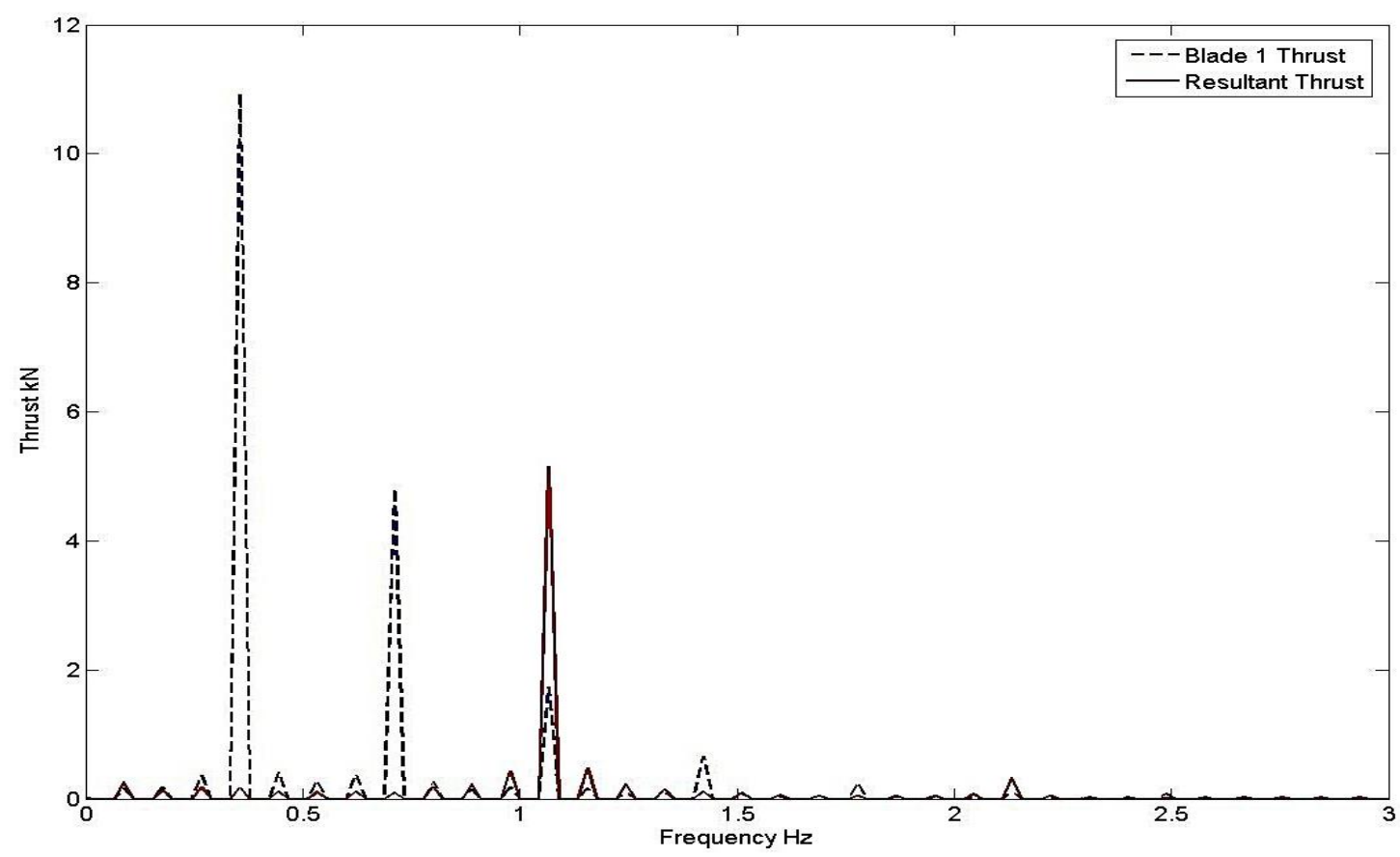

Figure 12: Frequency spectrum for the axial thrust loading on the turbine for theFSI model showing frequency spectrum associated with a single blade (blue) and the resultant (red) . 


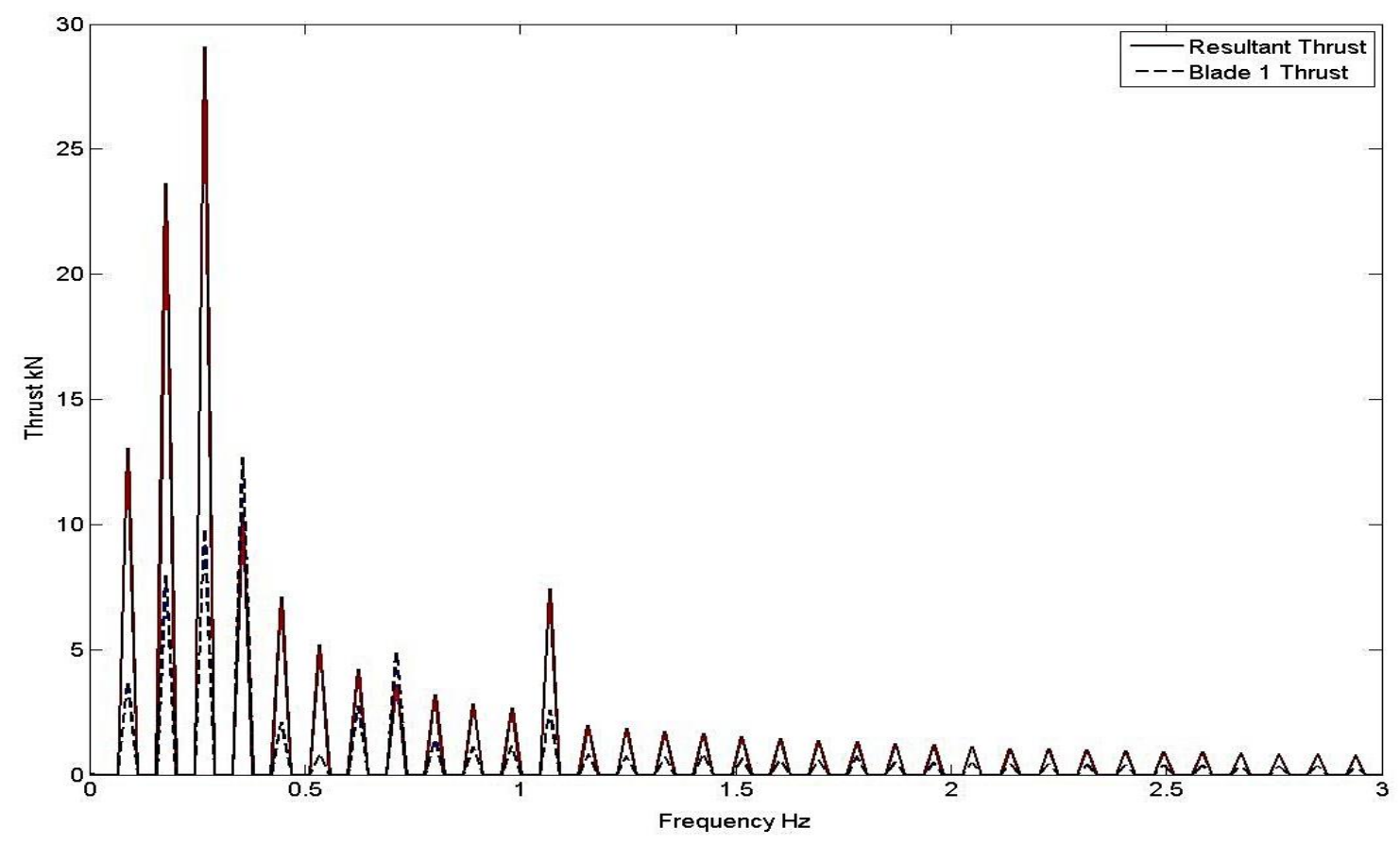

Figure 13 : Frequency spectrum for the axial thrust loading on the turbine for theVOF model showing frequency spectrum associated with a single blade (blue) and the resultant (red) .

\section{Discussion}

The exact placement of a tidal turbine in the water column will be dependent on a number of issues. These issues include the design of the anchoring method, the seabed topography, the shipping needs, the environmental considerations, etc. What must be known is the velocity profile over a period of time including spring and neap tides, the approximate level of turbulence and a history of the wave characteristics. With this information not only can the device characteristics be determined, but also the extreme loadings under normal conditions. The fundamental effects of how the waves change the velocity of the water through the water column can be estimated from oceanographic text. However, the effects of these changes on a turbine are another matter.

The work discussed in this paper has shown that as expected the average thrust on the turbine and power generated are only affected by a small amount. It is interesting to note that the average thrust has a small increase of approximately $5 \%$, whilst the average power is reduced by approximately $5 \%$. The major problems arise, however, from the large increase in the fluctuations in these characteristics. It should be noted that the turbine was run at a constant rotational speed and with a fixed blade pitch angle, facts that would not be true in reality and that one or both could be varied in response to fluctuations. The structure's response time to wave induced velocity changes would still produce large fluctuations as the inertia effects of the rotor would play a significant role. The fluctuations will translate into increased wear and tear or fatigue on components of the turbine, so reducing the life expectancy of the device before maintenance would be required. The amplitude of the fluctuations is most likely related to the wavelength and celerity of the wave and would have to be designed for. It could be hypothesised that the waves cause low frequency fatigue, with turbulence causing high frequency fatigue under certain circumstances. This work has not included an ADCP 
derived velocity profile and wave combined. However, it can be further hypothesised that given the possibility of a high shear velocity profile through the water column and the increased loading amplitude the results discussed in this paper will only be exaggerated under such conditions.

The FSI model has provided an insight into the reaction of the turbine, specifically the blades, to the simple uniform velocity. Due to the material chosen for the blades, the deflections are relatively small at approximately $23 \mathrm{~mm}$, however there is a minor interaction with the structure as the blades pass in front of the stanchion. There are clearly fluctuations in the loading on the individual blades that cause a fluctuation in the deflection of the blades as it rotates. These fluctuations cause a 'pulsing' in the thrust transferred to the drive shaft, as well as a resultant bending moment. The consequences are likely to be a reduced life expectancy before maintenance would be required. If the results of a wave were superimposed onto the loads then the blade roots and drive shaft will be subjected to large fluctuations in loads and bending moments.

The frequency content of the loading and power output from the turbine, under both the wave and plug flow conditions, suggests that coincidence of the turbine rotational velocity with the wave frequency could lead to greater load and power fluctuations as well as increased peak loading. This could be significant for extreme load predictions and would require that turbine developers survey the wave climate at prospective development sights. This surveying process should then be carried out with the goal of observing the correlation between frequencies observed in the given wave climate and the expected rotational velocity range of the turbine. The finding also adds to the need for intelligent turbine control schemes to minimise wave load fluctuation. To further explore this notion further modelling of wave climates would be required. The more complex frequency characteristic in the wave loading case suggest that fatigue life predictions will be dependent on the wave climate at proposed turbine deployment sites and as such could be a function of a complex wave spectra. However, it is likely that the effect of the wave spectra will be band limited due to the limited depth of penetration of higher frequency waves.

\section{Conclusions}

This paper has discussed the influence of waves on a tidal turbine's characteristics. What is clear is that the waves change the time averaged values of power and thrust. However the magnitudes and period of the changes are most likely dependent on the wave definition, i.e. wavelength, amplitude and celerity.

The amplitude of the fluctuations in both the power and thrust become exaggerated with waves as the axial flow velocity is influenced by the wave's subsurface rotational component.

There is clearly a need to include waves in the modelling of marine devices provided the devices are within a water column depth, to the surface, of half the wavelength of a wave.

The results from the two-way coupled FSI models have shown no significant differences from those of the uncoupled CFD model. However, this phenomenon is not a construct of weak fluid structure coupling but is primarily a result of the unrealistic inflexibility of the blade material at that scale and will 
therefore require further investigation. This latter point is especially true with the introduction of waves as presented in this paper.

The frequency analysis has shown that the wave frequency creates a more complex thrust load spectra. The interaction of wave frequency and turbine rotational velocity should be considered both in terms of potential deployment sight surveying and turbine control.

\section{Acknowledgements}

The authors would like to express their gratitude for the support of EPSRC, WEFO, HPC Wales, Fujitsu, and Mabey Bridge Ltd. for their funding of the work. The support of ANSYS is also gratefully acknowledged.

\section{References}

[1] European Union Committee, 2008. 27th Report of Session 2007-08 - The EU's Target for Renewable Energy: $20 \%$ by 2020. London : The Stationery Office Limited

[2] DECC, 2012. UK Renewable Energy Roadmap Update 2012. London: Crown copyright, Dept of Energy \& Climate Change

[3] Carbon Trust, 2011. Accelerating Marine Energy: The potential for cost reduction: insights from the Carbon Trust Marine Energy Accelerator.

[4] de Laleu V, 2009. La Rance Tidal Power Plant. 40-year operation feedback - Lessons learnt BHA Annual conferencewww.british-hydro.org/downloads/La\%20Rance-BHA-Oct\%202009.pdf [accessed July 2014].

[5] Tidal Energy Limited, www.tidalenergyltd.com [accessed July 2014]

[6] Seagen Wales http://seagenwales.co.uk/description.php [accessed July 2014]

[7] Royal Haskoning, 2011. SeaGen Environmental Monitoring Programme Final Report [Online]. Available at: http://www.marineturbines.com/sites/default/files/SeaGen-EnvironmentalMonitoring-Programme-Final-Report.pdf [Accessed 2 March 2013]

[8] Mason-Jones A, Evans PS, O'Doherty T and O'Doherty DM, 2008 Characterisation of a Tidal Stream Turbine Design using CFD and ADCP. World Renewable Energy Conference, Glasgow.

[9] Morris CE, 2014. Influence of solidity on the performance, swirl characteristics, wake recovery and blade deflection of a horizontal axis tidal turbine. PhD Thesis, http://orca.cf.ac.uk/60952. Cardiff University.

[10] Pinet PR, 2009. Invitation to Oceanography (5th ed.). Jones \& Bartlett Publishers. p.237. ISBN 0-7637-5993-3

[11] Lewis M, Neill SP, Hashemi MR, 2014. Waves, wave direction and the tidal stream energy resource. TOS/ASLO/AGU Ocean Sciences meeting, 23-28 February 2014, Honolulu, Hawaii. http://www.eposters.net/pdfs/waves-wave-direction-and-the-tidal-stream-energy-resource.pdf [accessed July 2014].

[12] Myers LE and Bahaj, AS, 2012. An experimental investigation simulating flow effects in first generation marine current energy converter arrays. Renewable Energy, 37, 28-36

[13] Nicholls-Lee RF, Turnock SR, Boyd SW, 2011. A method for analysing FSI on a HATT. $9^{\text {th }}$ European Wave and Tidal Energy Conference. Southampton, 5-9 September 2011.

[14] Park SW, Park S, Rhee SH, 2013. Performance Predictions of a Horizontal Axis Tidal Stream Turbine Considering the Effects of Blade Deformation. $3^{\text {rd }}$ International Symposium on Marine Propulsors. Launceston, 5-8 May 2013.

[15] Mason-Jones A, O'Doherty DM, Morris CE, O'Doherty T. 2012 Influence of a velocity profile \& support structure on tidal stream turbine performance. Renewable Energy, DOI 10.1016/j.renene.2012.10.022 
[16] Frost C, Morris CE, Mason-Jones A, O'Doherty DM, O'Doherty T. Effects of tidal directionality on tidal turbine characteristics. [Under review $\mathrm{J}$ of Renewable Energy, 2014]

[17] Mason-Jones A, O'Doherty DM, Morris CE, O'Doherty T, Byrne CB, Prickett PW, Grosvenor RI, Owen I, Tedds S, Poole RJ, 2012. Non-dimensional Scaling of tidal stream turbines. Energy, DOI 10.1016/j.energy.2012.05.0102012.

[18] Tedds SC, Poole RJ, Owen I, Najafian G, Mason-Jones A, Morris CE, O'Doherty T and O'Doherty DM. 2011 Experimental investigation of horizontal axis tidal stream turbines. $9^{\text {th }}$ EWTEC, Southampton (2011).

[19] British Oceanographic Data Centre (2013). Wave data series for Cardigan Bay, Port Talbot, The Mumbles, Gower and the Severn Estuary. Liverpool: British Oceanographic Data Centre

[20] Méhauté, B., 1976, An Introduction to Hydrodynamics and Water Waves, New York: SpringerVerlag.

[21] Wheeler, J.D. (1969). Method for calculating forces produced by irregular waves. Preprints 1969 Offshore Technology Conference, 1(1007): 83-94

[22] American Petroleum Institute (2000). Recommended Practice for Planning, Designing and Constructing Fixed [20] Offshore Platforms API-RP2A, 21st ed. API: Washington, D.C., U.S.A. United States Army Corps of Engineers, 1984. Shore protection manual. Department of the Army, Mississipi, U.S.A

[23] Pedlosky J, 2003. Waves in the Ocean and Atmosphere - Introduction to Wave Dynamics. Springer-Verlag, New York.

[24] Oppenheim, A.V., Willsky, A.S., Nawab, S.H., 1997. Signals \& systems. Prentice Hall, Upper Saddle River, N.J.

[25] Smith, S.W., 1997. The scientist and engineer's guide to digital signal processing, 1st ed. ed. California Technical Pub, San Diego, Calif. 